\title{
Erratum to: Sparse Representation Shape Models
}

\author{
Yuelong Li · Jufu Feng $\cdot$ Li Meng • Jigang Wu
}

Published online: 14 December 2013

(C) Springer Science+Business Media New York 2013

\section{Erratum to: J Math Imaging Vis}

DOI 10.1007/s10851-012-0394-3

There are two National Natural Science Foundation of China grants that should have been acknowledged on the title page of this article in addition to the one already acknowledged.

The additional National Natural Science Foundation of China grants numbers are 61302127 and 11326198 . In addition, this work is also supported by the Tianjin City High School Science and Technology Fund Planning Project (20120805).

The online version of the original article can be found under doi:10.1007/s10851-012-0394-3.

Y. Li $(\varangle) \cdot$ J. Wu

School of Computer Science and Software Engineering,

Tianjin Polytechnic University, Tianjin, P.R. China

e-mail: liyuelong@pku.edu.cn

Y. Li

e-mail: yuelong_li@126.com

J. Feng

Key Laboratory of Machine Perception (MOE),

School of Electronics Engineering and Computer Science,

Peking University, Beijing, P.R. China

L. Meng

Automobile Transport Command Department,

Military Transportation University, Tianjin, P.R. China 